Cahiers $d u$ MONDE RUSSE

\section{Cahiers du monde russe}

Russie - Empire russe - Union soviétique et États indépendants

45/3-4 | 2004

Varia

\title{
Anastasija Sergeevna Tumanova, Samoderžavie i obščestvennye organizacii v Rossii, 1905-1917 gody
}

\author{
Michel Tissier
}

\section{OpenEdition}

\section{Journals}

Édition électronique

URL : https://journals.openedition.org/monderusse/4187

DOI : 10.4000/monderusse.4187

ISSN : $1777-5388$

\section{Éditeur}

Éditions de l'EHESS

\section{Édition imprimée}

Date de publication : 1 juillet 2004

Pagination : 660-662

ISBN : 2-7132-2009-2

ISSN : $1252-6576$

Référence électronique

Michel Tissier, «Anastasija Sergeevna Tumanova, Samoderžavie i obščestvennye organizacii v Rossii, 1905-1917 gody », Cahiers du monde russe [En ligne], 45/3-4 | 2004, mis en ligne le 02 juin 2009, consulté le 03 septembre 2022. URL : http://journals.openedition.org/monderusse/4187 ; DOI : https://doi.org/10.4000/monderusse.4187

Ce document a été généré automatiquement le 3 septembre 2022.

Tous droits réservés 


\title{
Anastasija Sergeevna Tumanova, SamoderŽavie i obščestvennye organizacii v Rossii, 1905-1917 gody
}

\author{
Michel Tissier
}

\section{RÉFÉRENCE}

Anastasija Sergeevna TUMANOVA, Samoderžavie i obščestvennye organizacii v Rossii, 1905-1917 gody. Monografija (L'autocratie et les « associations » en Russie, 1905-1917. Monographie) Tambov, Izd-vo TGU im. G.R. Deržavina, 2002, 488 p.

L'ouvrage qu'Anastasija Tumanova a consacré aux «associations» (obščestvennye organizacii), à travers la politique menée par l'autocratie à leur égard au début du xxe siècle, vient combler une lacune importante de la littérature historique sur l'Ancien Régime russe. La persistance de cette lacune était même étonnante, tant la question de l'existence et du dynamisme d'une "société civile » dans la Russie prérévolutionnaire a occupé la recherche historique depuis le début des années 1980 au moins. Il est vrai que, parmi les historiens russes de la nouvelle génération, à laquelle l'auteur appartient, c'est une problématique plus récente, qui s'inspire en partie des travaux menés par les universitaires occidentaux, anglophones en particulier. Anastasija Tumanova s'est donc donné la tâche considérable de reprendre le problème en étudiant pour la première fois de manière systématique le statut de ces "associations" et les perspectives nouvelles qui s'ouvraient à leur activité dans les années qui précèdent la guerre et la révolution¹.

La traduction de l'expression russe obščestvennye organizacii et l'explication de la réalité qu'elle recouvre présentent une difficulté classique pour le lecteur francophone. Ce qui est au cœur de cette réalité, c'est la prise en compte de l'intérêt " public ». Ceci pose naturellement la question des relations entre l'État et ce qui n'est pas l'État. Fait d'histoire, qui tient aux conditions d'émergence de la démocratie en France sous sa forme républicaine, l'usage en français rapporte volontiers à l'État tout ce qui est 
caractérisé comme " public ». La langue russe au xixe et au début du xxe siècle, avec le substantif obščestvo et ses dérivés, procède autrement, en mettant au contraire en opposition la « société » éduquée et l'État pour la prise en charge de l'intérêt général et du bien public.

C'est précisément l'objet du premier chapitre du livre d'A. Tumanova que de décrire, sous forme d'introduction au propos principal, le développement - à la fin du xixe siècle - de cette concurrence entre la bureaucratie impériale et les divers groupements d'origine privée qui ne pouvaient pas légalement exister ni faire quoi que ce soit sans son autorisation. Avec la contestation croissante du rôle central de l'administration, ces groupements furent caractérisés comme fondamentalement «non étatiques » ou « non bureaucratiques». Il est donc délicat de les désigner en français comme des « organisations publiques».

Si l'on ne craignait pas l'anachronisme, le plus efficace serait peut-être de parler ici d'« organisations non gouvernementales". Mais A. Tumanova circonscrit très précisément l'objet de son étude aux groupements créés dans un but non commercial par des particuliers qui s'associent pour promouvoir une œuvre d'intérêt général ou collectif - qu'il s'agisse d'éducation, de science, d'art et de culture, de santé, de loisirs, de formation professionnelle, de bienfaisance ou d'entraide mutuelle, voire de représentation syndicale des intérêts professionnels. Ce qui correspond assez bien au contenu exactement contemporain de la loi adoptée en France en 1901, relative, entre autres, au contrat d'association, et justifie l'analogie entre le cas russe et celui des " associations » françaises. La mention des expériences étrangères contemporaines de la période étudiée par l'auteur est d'ailleurs importante dans son propos. A. Tumanova fournit notamment une présentation précise de l'influence qu'ont eue les différents modèles juridiques occidentaux dans l'élaboration de la législation russe.

En règle générale, l'approche choisie par l'auteur consiste à suivre les développements de cette législation et de la pratique administrative dans le contexte ouvert par les aspirations à une libéralisation du régime, et surtout par l'ébranlement révolutionnaire de 1905. Cela signifie que les "associations " prises en compte sont celles qui ont une existence légale au sens de la réglementation que le gouvernement russe adopte, à titre provisoire en théorie, en 1906. À une exception près, très importante mais aisément compréhensible : les partis politiques, qui relèvent pourtant de la même législation, sont exclus du propos. Avec une telle définition institutionnelle des " associations ", l'étude d'A. Tumanova ne vise évidemment pas à embrasser tout le champ, impossible à délimiter selon des critères formels, de la "société civile » autoproclamée de l'époque. Celle-ci englobait également d'autres types d'acteurs, collectifs ou non, que l'auteur évoque brièvement dans son premier chapitre, qu'il s'agisse des journaux et revues, des éditeurs, mais aussi des institutions d'autonomie locale, ou des organes de représentation des ordres constitués.

En privilégiant ainsi l'aspect institutionnel, A. Tumanova livre une riche contribution à une démarche historiographique qu'elle partage avec d'autres historiens russes, et dont le but est, globalement, de réhabiliter l'action réformatrice de l'administration russe à la fin de l'empire. L'auteur mentionne certes, mais pour les minimiser, les tergiversations et les résistances du régime. Celles-ci sont présentées plutôt comme des " contradictions " et des « inconséquences » internes, et non comme des éléments susceptibles de remettre en cause l'œuvre de "modernisation constitutionnelle », qui s'appuie sur une expertise juridique de l'administration impériale de grande qualité. Le cœur du livre est ainsi 
consacré à une analyse extrêmement détaillée des tenants et des aboutissants de la politique russe envers les associations. Le chapitre II porte sur l'élaboration de la législation sur les associations en 1905-1906 et sur la part que les divers organes de l'État y ont prise. L'auteur y décrit très clairement les conditions dans lesquelles a été fixé le régime juridique pour la création et la fermeture des associations, marqué au final par une prééminence de la logique administrative. Le chapitre III constitue un examen des moyens et des formes du contrôle, par la police politique du ministère de l'Intérieur, des associations, que l'auteur distingue suivant leurs différents domaines d'activité, des associations éducatives aux groupes d'espérantistes, en passant par les clubs automobiles et aéronautiques. Le chapitre IV, le plus novateur, est une analyse de la pratique administrative des autorités locales envers les associations. Là, Tumanova met en valeur les interactions entre autorités et associations, qui prennent parfois la forme d'une coopération.

L'auteur démontre de façon convaincante que les organes centraux du gouvernement sont plus préoccupés de trouver un cadre viable pour l'application de la «liberté d'association » officiellement proclamée, que ne le sont les fonctionnaires locaux, dont la tendance à perpétuer les anciennes pratiques administratives est très forte. La législation en vigueur ne satisfaisait pas grand monde au total. Le cinquième et dernier chapitre présente justement la confrontation entre les autorités gouvernementales et les forces politiques d'opposition, à la Douma et dans la presse, sur le régime juridique de la liberté d'association et sur les divers projets pour le réformer. Tout en reconnaissant l'absence d'avancées significatives dans la politique du gouvernement, A. Tumanova défend globalement cette dernière contre les attaques maximalistes des libéraux russes, en rappelant la prise en compte par le pouvoir des « conditions politiques et juridiques spécifiques » de la Russie à l'époque.

Cependant, les faits révélés par les analyses très poussées de l'auteur font paradoxalement naitre quelques doutes sur la cohérence des conclusions qu'elle en tire. Le propos est apparemment nuancé, mais on se demande s'il ne vise pas à concilier l'inconciliable. N'y a-t-il pas une illusion à considérer que, dans une société « moderne " telle que le gouvernement voulait la construire, mais sans perdre ses prérogatives, une séparation des tâches pouvait être effectivement instituée entre l'État, d'une part, et la "société civile» et les associations, d'autre part? Selon ce schéma, les associations auraient dû rester cantonnées hors du politique et de la politique. Or tout l'ouvrage d'A. Tumanova montre bien que la question politique est très souvent difficilement dissociable de l'activité des nombreuses associations créées en Russie au début du xxe siècle. C'est même la première préoccupation des autorités centrales et locales, qui dépensent toute leur énergie à discerner le bon grain de l'ivraie entre les associations qui «font de la politique » et celles qui n'en font pas. Mais cela ne constitue en rien une spécificité russe, et il y a bien des exemples comparables dans l'histoire moderne des États européens. Il y a donc là toute une réflexion à mener sur la pertinence de la conception qui fait de la liberté d'association et de son application un principe « civil » et non "politique", ainsi que sur l'influence que cette conception a eue et continue d'avoir en Russie.

Le livre comprend un index des noms de personnes - mais pas d'index des associations citées, malheureusement -, et plusieurs documents intéressants sont fournis en annexe, à commencer par le texte des règlements provisoires de 1906. On peut regretter que la lecture de ce travail très précis, mais long et assez austère, ne soit pas facilitée par un 
découpage et une présentation plus analytiques. C'est en tous cas une mine de renseignements sur l'activité des associations russes du début du xxe siècle. Enfin, les historiens disposent là d'un ouvrage de référence sur la législation et la pratique administrative, dans un domaine essentiel à la juste appréciation de la place réellement tenue par la « société civile » à la fin de l'empire russe.

\section{NOTES}

1. Le lecteur francophone a déjà pu prendre connaissance d'un article de l'auteur dans une livraison récente des Cahiers $d u$ Monde russe, consacrée aux intellectuels et à l'intelligentsia. Il s'agit d'un "essai d'étude régionale », centré sur la ville de Tambov, dont la problématique est très différente de celle du livre. C'est en effet davantage une description de l'activité des associations locales, désignées comme des organisations "typiques " à l'échelle de la Russie européenne: Anastasija S. Tumanova, "L'intelligentsia et son rôle dans les organisations publiques de la ville de Tambov au tournant du xxe siècle », CMR, 43 (4), Octobre-décembre 2002, p. 645-659. 